\title{
A LIFE SENTENCE OR PAROLE: CONDITIONAL RELEASE APPROVAL OF BIOLOGICAL CONTROL AGENTS
}

\author{
S.A. WHITEMAN ${ }^{1}$, B.I.P. BARRATT ${ }^{2}$ and G.S. RIDLEY ${ }^{1}$ \\ ${ }^{1}$ ERMA New Zealand, PO Box 131, Wellington, New Zealand \\ ${ }^{2}$ AgResearch, Invermay Agricultural Centre, Private Bag 50 034, Mosgiel, \\ New Zealand
}

Corresponding author: geoff.ridley@ermanz.govt.nz

\begin{abstract}
Changes made in 2003 to the Hazardous Substances and New Organisms (HSNO) Act 1996 introduced a new approval type called 'conditional release'. Previously, the only option was for 'full release' approval under which the organism was no longer subject to HSNO Act regulation. Applicants seeking approval for conditional release of a biological control agent have expressed concern that a resulting approval may have onerous and costly controls required for risk mitigation. In 2005 Microctonus aethiopoides, a biological control agent of Sitona lepidus (clover root weevil), became the first organism to be granted a conditional release approval. This paper discusses the controls on that approval and other possible options for controls that could be considered in the future.

Keywords: Irish parthenogenetic strain, Microctonus aethiopoides, Sitona lepidus, clover root weevil, biological control agent.
\end{abstract}

\section{INTRODUCTION}

Since the introduction of the Hazardous Substances and New Organisms (HSNO) Act 1996 researchers wishing to import into New Zealand new organisms for biological control are required to obtain an approval for both research in containment and for full release into the environment. A key feature of an approval for full release is that anyone else is then able to release the same organism into New Zealand without (re-) application. The full process for obtaining HSNO Act approvals for biological control agents has been reviewed by Barratt \& Moeed (2005).

Conditional release is a relatively new category of approval introduced in 2003 following amendments to the HSNO Act after a report from the Royal Commission (2002). Conditional release allows staff of the Environmental Risk Management Authority (ERMA New Zealand), who implement the HSNO Act, to place risk-mitigating controls on approvals to release organisms into the environment. This was not possible under the full release option. Because conditional release approvals allow some level of control they can be viewed as a half-way house between the highly restrictive nature of approval to carry out research in containment and approval for full release in the absence of any restrictions. The conditional release concept is intended to reduce the risks of new organisms to acceptable levels that would otherwise be unacceptable under a full release option. In this way the objectives of the Royal Commission (2002) of preserving opportunities and proceeding selectively with appropriate care are achieved.

When applying for approval for full release of any new organism, an applicant must justify why conditional release was not considered. If a conditional release approval is applied for, the applicant must suggest appropriate risk-mitigating controls. However, as part of their risk assessment, ERMA New Zealand may choose to add additional controls to manage risk. 
Four key considerations must be taken into account when developing controls for conditional releases:

- Controls must be applied for the purposes of mitigating risk.

- Controls must be practical so that the applicant can reasonably be expected to be able to comply with them.

- Controls must be cost-effective so that the cost of complying with the controls does not exceed the benefits associated with the organisms approved.

- Controls must be enforceable to allow auditing of compliance.

This paper reviews the first conditional release approval of a biological control agent, Microctonus aethiopoides Loan parthenogenetic strain from Ireland, for the control of Sitona lepidus Gyllenhal (clover root weevil). Particular emphasis has been given to the risk assessment that led to the requirement for a control to manage risk.

\section{CONDITIONAL RELEASE - AN EXAMPLE IN PRACTICE}

The first HSNO Act approval for the conditional release of a biological control agent was for the parthenogenetic strain of Microctonus aethiopoides Loan from Ireland, for the control of Sitona lepidus Gyllenhal (clover root weevil). The rationale for the conditional release application is provided by Gerard et al. (2006). A conditional release application was preferred because a full release approval could allow subsequent releases of non-parthenogenetic strains of the European biotype of $M$. aethiopoides. Such strains might then hybridise with the existing Moroccan biotype used in New Zealand for the control of lucerne weevil, Sitona discoideus, and reduce the efficacy of both biotypes (Goldson et al. 2003).

The risk assessment for the parthenogenetic strain of $M$. aethiopoides from Ireland considered that the presence of other, non-parthenogenetic strains in New Zealand could result in a loss of control of lucerne weevil with the following associated effects:

- Environmental contamination due to increased use of insecticides (especially broadspectrum organophosphates) for the control of lucerne weevil.

- Human health effects due to increased use of insecticides (especially organophosphates) for the control of lucerne weevil.

- Market economy effects due to the increased costs of managing lucerne weevil due to loss of the estimated $\$ 6$ million per annum benefits to the pastoral industry currently achieved by the Moroccan strain of the parasitoid.

These effects were of sufficient significance that ERMA New Zealand agreed with the applicant's request to impose a risk mitigating control that specificially limited the approval to the importation and release of parthenogenetic individuals of $M$. aethiopoides from Ireland. The exact wording of the control is presented below, and includes the option to review the control should new methodologies, such as genetic markers, be developed that would aid in the identification of the parthenogenetic strain:

"Users of this approval shall provide to the Ministry of Agriculture and Forestry facility supervisors of the containment facility (or equivalent authorised person) into which new populations of $M$. aethiopoides (Irish) are imported, results verifying that individuals are parthenogenetic. The method used shall be scientifically valid and peer reviewed. The current agreed method is presented below but as allowed in section $38 \mathrm{G}$ [of the HSNO Act] may be reviewed.

All individual $M$. aethiopoides being assessed for parthenogenesis should be derived from or reared from S. lepidus collected in the field in Ireland. Each individual parasitoid should be exposed to 30-40 Sitona lepidus weevils for 48 hours in cages furnished with white clover. All $M$. aethiopoides progeny derived from this exposure to $S$. lepidus should be female, the gender having been determined by microscopic examination using the descriptions of Loan (1975). Determination of parthenogenesis shall be verified for at least two consecutive generations. Where parthenogenesis is determined in New Zealand, as opposed to overseas, testing should be done in a containment facility registered according to the MAF/ERMA New Zealand Standard 154.02.08." 
Because this is an approval for conditional release, the Irish strain remains a "new organism' (under the HSNO Act). However neither the approval nor the control expires. As such, because the organism remains regulated, concerns have been raised that compliance costs (e.g. continuing auditing, reporting, etc) will be incurred. It is hoped that these concerns will be partly allayed by the observation that in the case of the $M$. aethiopoides parthenogenetic strain from Ireland approval, the only HSNO Act requirement was something that the applicant had intended to do voluntarily.

\section{CONCLUSION}

Initially applicants from the biological control research community were reluctant to consider conditional release. Many viewed the imposition of controls as a penalty rather than a risk mitigation measure. The approval for conditional release of the $M$. aethiopoides parthenogenetic strain from Ireland has done much to allay concerns about the restrictive nature of conditional release approval. Instead of seeing controls as a penalty, researchers are beginning to see the potential opportunities conditional release provides, and are currently considering opportunities for extending the possible range of control options. As a result ERMA New Zealand has noted a change of opinion in the research community, and it is predicted that conditional release will become the favoured option

A recent initiative $(B 3,2005)$ to further identify options that could be used in conditional release controls resulted in the following list of options:

1. Pre-border controls, for example sourcing biological control agents from a specific geographical location so that biotype differences do not become a source of risk (e.g. as used for the M. aethiopoides parthenogenetic strain from Ireland outlined above).

2. Geographical isolation - releasing a biological control agent in a small area (e.g. an island) where it is isolated from most of New Zealand while non-target effects are examined.

3. Physical isolation - releasing a biological control agent into large field cages which preclude its escape. These remain artificial environments, but are closer to a natural situation than can be currently achieved in containment.

4. Physiological limitation, such as Sterile Insect Technique - releasing insects which are unable to reproduce, so that risks can be limited to a single generation while allowing researchers to examine the potential for risk to the environment.

5. Eradication - developing 'fail safe' eradication methods so that if unacceptable adverse impacts are observed post-release, the biological control agent can be removed from the environment.

6. Post-release monitoring - developing tools for monitoring (what to measure, when, and how to respond).

7. Community and cultural participation - encouraging community involvement in activities such as monitoring, ensuring recognition of Maori taonga (treasured species), educating the public about what can and can not be achieved via conditional release.

Not all of the above options may be feasible or environmentally desirable, but they illustrate the potential breadth of possibilities for conditional releases. ERMA New Zealand is part of a project team working with researchers to prioritise these research options, which it is hoped will contribute to the development of new technologies and techniques for risk-mitigating controls. It is predicted that conditional release will become the favoured option for biological control programmes. 


\section{REFERENCES}

B3 2005. B3 'Better Border Biosecurity Science to protect New Zealand's plants'. http://www.b3nz.org/ (accessed 15 May 2006).

Barratt BIP, Moeed A 2005. Environmental safety of biological control: Policy and practice in New Zealand. Biological Control 35: 247-252.

Gerard PJ, McNeill MR, Barratt BIP, Whiteman SA 2006. Rationale for release of the Irish strain of Microctonus aethiopoides for biocontrol of clover root weevil. New Zealand Plant Protection 59: 285-289.

Goldson SL, McNeill MR, Proffitt JR 2003. Negative effects of strain hybridisation on the biocontrol agent Microctonus aethiopoides. New Zealand Plant Protection 56: $138-142$.

Loan, CC 1975. A review of Haliday species of Microctonus [Hym.: Braconidae, Euphorinae]. Entomophaga 20: 31-41.

Royal Commission on Genetic Modification 2002. Report of the Royal Commission on Genetic Modification. New Zealand Ministry for the Environment, Wellington, New Zealand. http://www.mfe.govt.nz/publications/organisms/royal-commission-gm/ (accessed 29 November 2005). 